\title{
Visual representation of National Institute of Allergy and Infectious Disease and Food Allergy and Anaphylaxis Network criteria for anaphylaxis
}

\author{
Veena Manivannan • Wyatt W. Decker • \\ Latha G. Stead • James T. C. Li • Ronna L. Campbell
}

Received: 28 January 2009 / Accepted: 2 February 2009/Published online: 25 February 2009

(C) Springer-Verlag London Ltd 2009

\begin{abstract}
We present a user-friendly visual representation of The National Institute of Allergy and Infectious Disease and the Food Allergy and Anaphylaxis Network criteria so as to enhance recognition of anaphylaxis and active teaching and learning.
\end{abstract}

Keywords Anaphylaxis · Criteria for diagnosis

Anaphylaxis is a potentially fatal acute systemic allergic reaction. It is becoming increasingly common. [1, 2] Multiple studies have shown that anaphylaxis is both under-recognized and under-treated. [3-5]

Anaphylaxis is known to have varied presentations involving different organ systems. There are no universally accepted criteria for diagnosis of anaphylaxis. Lack of standardized diagnostic criteria has hampered diagnosis and management of anaphylaxis. The National Institute of Allergy and Infectious Disease and the Food Allergy and

Criteria reproduced with the kind permission of the Mayo Foundation for Medical Education and Research.

V. Manivannan · W. W. Decker $\cdot$ R. L. Campbell $(\bowtie)$

Department of Emergency Medicine, Mayo Clinic,

200 First Street SW,

Rochester, MN 55905, USA

e-mail: campbell.ronna@mayo.edu

L. G. Stead

Department of Emergency Medicine,

University of Rochester School of Medicine and Dentistry,

Rochester, NY, USA

J. T. C. $\mathrm{Li}$

Division of Allergic Diseases and the Division

of Infectious Diseases, Mayo Clinic,

Rochester, MN, USA
Anaphylaxis Network (NIAID/FAAN) organized an international symposium in 2005 at which new diagnostic criteria for anaphylaxis were proposed. Although not prospectively validated, these criteria provide physicians with a rapid and simplified means of making the diagnosis.

Traditionally, the term 'anaphylaxis' referred to lifethreatening manifestations of allergic reactions, such as respiratory distress or shock (anaphylactic shock) as manifested by hypotension or signs of hypoperfusion of critical organs. However, there is now a growing consensus that anaphylaxis is a systemic allergic reaction that typically involves more than one organ system but rarely can present with cardiovascular compromise as the only symptom. Therefore, the new criteria will capture broader presentations, encompassing less severe manifestations.

The importance of recognition and diagnosis of mild presentations of anaphylaxis (for example, rash and vomiting after an allergen exposure) is underscored by a study by Pumphrey. [6] In this study of 139 fatalities due to anaphylaxis, $78 \%$ of deaths attributed to food allergy, and $82 \%$ of deaths attributed to venom allergy occurred in patients with no previous history of severe allergic reactions. These fatalities might have been prevented if the previous less severe presentations had been recognized and patients had been provided with self-injectable epinephrine and appropriate follow-up referrals.

Table 1 shows the NIAID/FAAN criteria. [7] Patients are likely to have anaphylaxis if any one of the three criteria is present. It was believed that the criteria would "capture more than $95 \%$ of cases of anaphylaxis". [7]

We present a user-friendly visual representation (Fig. 1) of the NIAID/FAAN criteria so as to enhance, not only recognition of anaphylaxis, but also active teaching and learning of these criteria among health-care providers. Increased recognition and diagnosis of anaphylaxis will 
Table 1 National Institute of Allergy and Infectious Disease and Food Allergy and Anaphylaxis Network criteria for anaphylaxis

Anaphylaxis is likely when any one of these three criteria is fulfilled:

1. Acute onset of illness (minutes to several hours) with involvement of the skin, mucosal tissue, or both (e.g., generalized hives, pruritus or flushing, swollen lips, tongue, or uvula)

and at least one of the following:

(a) Respiratory compromise (e.g., dyspnea, wheeze or bronchospasm, stridor, reduced peak expiratory flow, hypoxemia)

(b) Reduced blood pressure or associated symptoms of end-organ dysfunction (e.g., hypotonia [collapse], syncope, incontinence)

2. Two or more of the following that occur rapidly after exposure to a likely allergen for that patient (minutes to several hours):

(a) Involvement of the skin or mucosal tissue (e.g., generalized hives, itch or flush, swollen lips, tongue, or uvula)

(b) Respiratory compromise (e.g., dyspnea, wheeze or bronchospasm, stridor, reduced peak expiratory flow, hypoxemia)

(c) Reduced blood pressure or associated symptoms (e.g., hypotonia [collapse], syncope, incontinence)

(d) Persistent gastrointestinal tract symptoms (e.g., crampy abdominal pain, vomiting)

3. Reduced blood pressure after exposure to known allergen for that patient (minutes to several hours):

(a) Infants and children: low systolic blood pressure (age specific) or $>30 \%$ decrease in systolic blood pressure ${ }^{\mathrm{a}}$

(b) Adults: systolic blood pressure $<90 \mathrm{mmHg}$ or $>30 \%$ decrease from that person's baseline

${ }^{a}$ Low systolic blood pressure for children is defined as $<70 \mathrm{mmHg}$ from 1 month to 1 year, $<(70 \mathrm{mmHg}+[2 \times$ age $])$ from 1 to 10 years, and $<90 \mathrm{mmHg}$ from 11 to 17 years.

Modified from Sampson et al. [7]
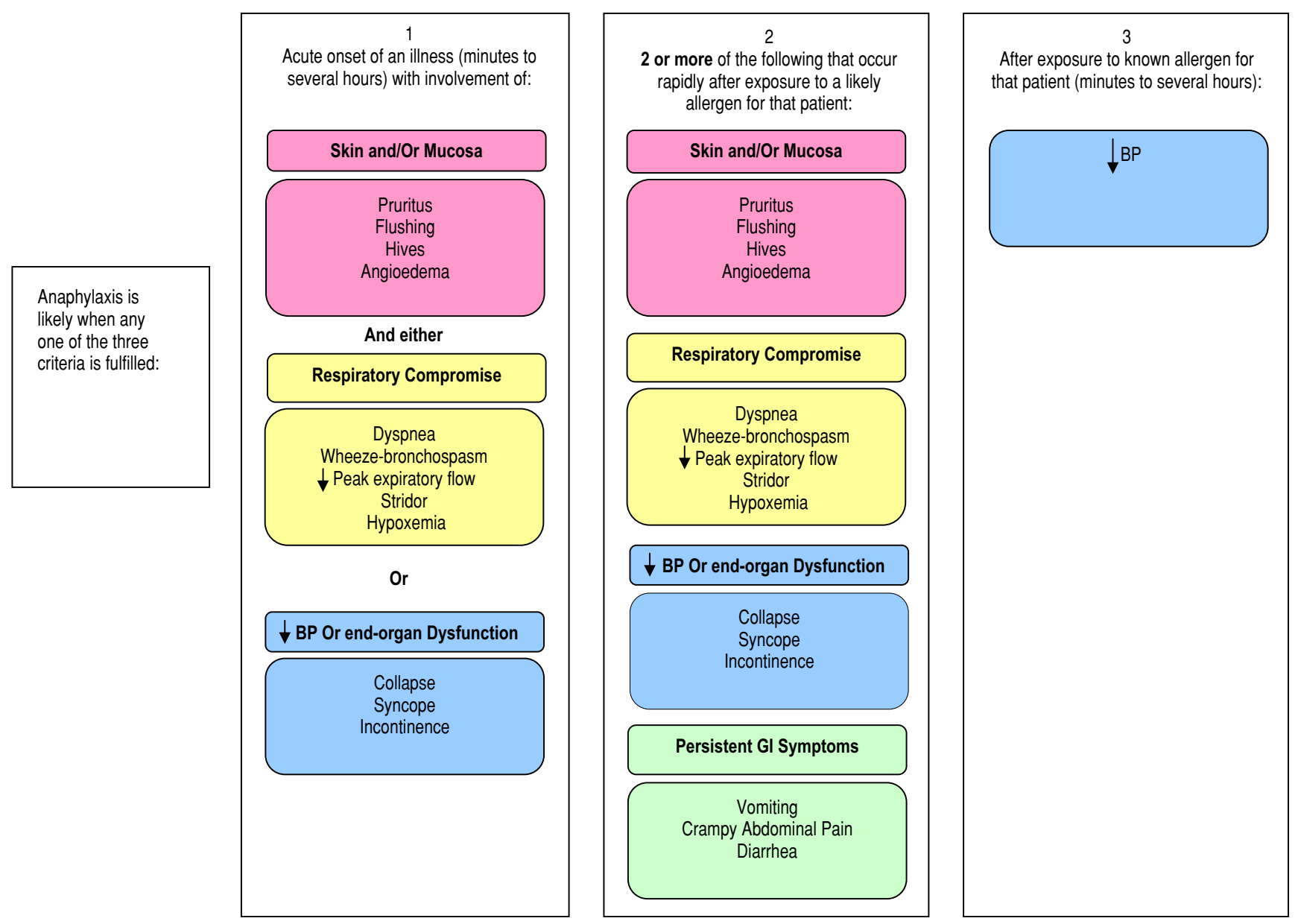

Fig. 1 Visual representation of the National Institute of Allergy and Infectious Disease and Food Allergy and Anaphylaxis Network criteria for anaphylaxis 
hopefully lead to improved management and better outcomes in patients suffering from anaphylaxis.

\section{References}

1. Decker WW, Campbell RL, Manivannan V, Luke A, St Sauver JL, Weaver A et al (2008) The etiology and incidence of anaphylaxis in Rochester, Minnesota: a report from the Rochester Epidemiology Project. J Allergy Clin Immunol 122:1161-1165

2. Lieberman P (2008) Epidemiology of anaphylaxis. Curr Opin Allergy Clin Immunol 8:316-320

3. Campbell RL, Luke A, Weaver AL, St Sauver JL, Bergstralh EJ, Li JT, Manivannan V, Decker WW (2008) Prescriptions for self- injectable epinephrine and follow-up referral in emergency department patients presenting with anaphylaxis. Annals of Allergy, Asthma \& Immunology 101(6):631-636, Dec

4. Klein JS, Yocum MW (1995) Underreporting of anaphylaxis in a community emergency room. J Allergy Clin Immunol 95:637-638

5. Lieberman P, Camargo CA, Jr., Bohlke K, Jick H, Miller RL, Sheikh A et al (2006) Epidemiology of anaphylaxis: findings of the American College of Allergy, Asthma and Immunology Epidemiology of Anaphylaxis Working Group. Ann Allergy Asthma Immunol 97:596-602

6. Pumphrey RS (2000) Lessons for management of anaphylaxis from a study of fatal reactions. Clin Exp Allergy 30:1144-1150

7. Sampson HA, Munoz-Furlong A, Campbell RL, Adkinson NF, Jr., Bock SA, Branum A et al (2006) Second symposium on the definition and management of anaphylaxis: summary report-Second National Institute of Allergy and Infectious Disease/Food Allergy and Anaphylaxis Network symposium. J Allergy Clin Immunol 117:391-397 